\title{
The Regulation of Non-Invasive Prenatal Testing (NIPT) in France: Continuity and Changes in the Development of Prenatal Testing
}

Carine Vassy ${ }^{1,}{ }^{*}$, Laurence Brunet ${ }^{2}$, Christine Noiville ${ }^{2}$

1. Université Sorbonne Paris Nord, IRIS, EHESS, CNRS, UMR 8156, Inserm U997, 74 rue Marcel Cachin, 93000 Bobigny, France; E-Mail: carine.vassy@univ-paris13.fr

2. Institut des Sciences Juridiques et Philosophiques de La Sorbonne, Université Paris 1 CNRS, UMR 8103, 1 rue de la glacière, 75013 Paris, France; E-Mails: laurence.brunet005@gmail.com; noiville@univ-paris1.fr

* Correspondence: Carine Vassy; E-Mail: carine.vassy@univ-paris13.fr

Academic Editors: Diane B. Paul and Ilana Löwy

Special Issue: Policy Issues in Prenatal and Neonatal Testing, Counseling, and Decision-Making

OBM Genetics

2022 , volume 6 , issue 1

doi:10.21926/obm.genet.2201149
Received: September 02, 2021

Accepted: February 08, 2022

Published: February 25, 2022

\begin{abstract}
This article examines the regulation of the screening of fetal abnormalities in France before and after the implementation of the new technique of non-invasive prenatal testing (NIPT) in 2013. In addition, this article evaluates the effectiveness of the regulatory framework in addressing the ethical and social issues raised by this technique from a legal and sociological perspective. The analysis reveals that the regulations, consistent with that applied to other prenatal screening techniques, fail to take proper account of the following problems posed by NIPT: the continuing increase in the number of abnormalities detected in fetuses, the context of mounting pressure from the manufacturers, and the challenges involved in providing pregnant women with quality information that preserves their reproductive autonomy.
\end{abstract}

\section{Keywords}

Non-invasive prenatal testing (NIPT); regulation; prenatal screening; informed consent; France; ethics; reproductive autonomy

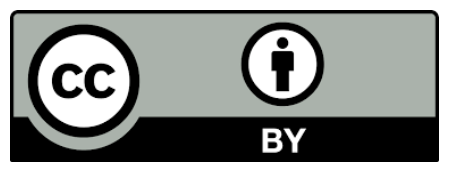

(C) 2022 by the author. This is an open access article distributed under the conditions of the Creative Commons by Attribution License, which permits unrestricted use, distribution, and reproduction in any medium or format, provided the original work is correctly cited. 


\section{Introduction}

Non-invasive prenatal testing (NIPT) is a newly developed genetic test designed to detect chromosomal anomalies in fetuses. Since its launch in 2011, NIPT has been commercially available in many countries [1], which is mainly due to the driving force of biotechnology companies manufacturing these tests [2,3]. These companies have applied for patents in various countries [4]. However, previous tests for testing and diagnosing fetal anomalies have not been patented and are less expensive.

Despite its high price, NIPT has been a commercial success because of its several advantages over conventional testing for trisomy 21 , such as serum markers ${ }^{1}$ and ultrasound scans, or a combination of both. This test involves the analysis of cell-free fetal DNA circulating in pregnant women's blood and provides reliable (fewer false positives and false negatives) results earlier in the pregnancy. Positive results must be confirmed by a diagnostic test, such as the fetal karyotype. Because of the lower false-positive results of NIPT, it offers the advantage of reducing the need for a diagnostic test. The latter requires invasive sampling, such as amniocentesis or trophoblast biopsy, thereby carrying a small risk of miscarriage.

The implementation of NIPT differs from country to country. Based on the versions, these tests can detect a variable number of more or less rare anomalies (only trisomy 21, or also trisomy 13 and 18 , or also rare trisomies, or even chromosomal microdeletions, etc.) with varying degrees of reliability [5]. Some of these chromosomal alterations lead to pathologies with varying seriousness.

In some countries, such as Brazil, extended versions of this test are available only at private health facilities, thereby limiting its use to women who can afford it out of their own pockets [3]. However, in some other countries, the test is paid for by private or public insurers, who may choose to restrict its use to the detection of certain pathologies among categories of pregnant women at higher risk of fetal anomalies [1,6]. According to Löwy [3], the variability in the implementation of NIPT across the world is because of the existent state-sponsored testing programs for trisomy 21. Such states are in a better position to consider the cost-effectiveness and reliability of the new tests and to either limit or extend them to the detection of particular fetal pathologies in certain categories of pregnant women.

This article describes the implementation of NIPT in France, where the role of the state, through public insurance, is traditionally significant [7]. The government, with the support of public agencies, makes decisions regarding prenatal testing and screening, such as which tests are funded for which categories of pregnant women. In contrast, the United States Food and Drug Administration (FDA) has not been involved in evaluating NIPT, leaving the industry to bargain with a large number of private and public insurers $[2,8]$. As in other European countries with large populations (England and Germany), the French government decided that conventional tests (serum markers and ultrasound scan) would be the first choice for prenatal testing and screening and that NIPT would be reimbursed as a secondary test for women found to be at risk based on conventional tests [6].

\footnotetext{
${ }^{1}$ These tests involve analysis of maternal blood for abnormal levels of hormones and proteins associated with a higher probability of fetal T21.
} 
This article examines the decision-makers in France and the reasons behind the decisions. In addition, the continuity and changes in state intervention in prenatal testing were analyzed. The introduction of new tests, such as NIPT, has reinforced the traditional criticisms of the prenatal screening policy. This paper examines whether the widespread use of NIPT provides an opportunity to change this policy.

Currently, two kinds of criticisms of prenatal screening policy exist. Initially, the public debate was marked by accusations of eugenics ${ }^{2}$, which were regularly reported in the media [6]. Another type of less prevalent criticism relates to the poor quality of the information provided to pregnant women during consultations, which may restrict their freedom of choice [10]. Under the regulations, health professionals must ensure that women provide their informed consent before testing. Some studies have indicated that women have insufficient knowledge of the tests they are undergoing, with some of them even believing that testing is mandatory [11, 12]. Insufficient knowledge often causes stress in women who receive the results of high-risk testing, even though these results are often false positives [13]. Associations of parents of children with T21 have criticized the adequacy of the information (which they find overly pessimistic) regarding test results provided to women [14]. In several countries, sociologists have demonstrated that informed consent is an ideal that is not easily achieved, as a result of the fact that testing is routinely offered $[15,16]$. This is especially true in France [17].

The implementation of NIPT has rekindled various arguments. An association of parents of T21 children argued in favor of funding research to treat T21 rather than developing tests like NIPT [14]. Some obstetricians have expressed concerns regarding the introduction of NIPT, as it would exacerbate the problems of information for pregnant women [18]. Furthermore, NIPT is detecting an increasing number of chromosomal alterations; however, not all of them lead to serious pathologies. Against the background of polarized ethical questions in France and social mobilizations whenever the fate of the human fetus is under discussion, what regulations have been put in place, and by whom, to guide the development of NIPT? Have there been any significant shifts from the regulation of previous prenatal screening techniques? Has there been a response to the recurrent criticism regarding the challenges faced by pregnant women to become aware of the available options in the early stages of their pregnancy and to consequently make informed choices? These are some of the issues addressed in this article.

This article will reveal that the regulation of the NIPT technique is an extension of the usual model of governance that, in the field of prenatal testing, gives considerable leeway for actors from the medical and manufacturing sectors. While committed to protecting the information and consent of pregnant women in the course of prenatal testing, the public authorities simply restrict themselves to endorsing practices regulated by the health professional community. This type of governance does not change much in the face of new challenges, such as the deployment of NIPT. Given the

2 It was in France that the chromosomal origin of trisomy 21 (T21) was discovered by Dr. Jérôme Lejeune and his colleagues in 1959. From the beginning of prenatal diagnosis, he campaigned against pregnancy terminations, particularly medical terminations of T21, with the support of the Catholic Church and part of the medical community [9]. Today, the Fondation Lejeune goes on with his efforts in the media. It denounces a eugenicist testing that strongly reduces the number of births with $\mathrm{T} 21$, which is supported by certain religious authorities, health professionals, and specialists in the human and social sciences. Nevertheless, such accusations are denied by others and also by the public authorities, who stress that testing has never been mandatory and that there is a significant social demand for it. 
possibility of testing for an increasingly wide range of anomalies in the fetus, several questions arise about women's reproductive autonomy, which is deemed to be the most legitimate parameter for regulation that respects individual choice. This is, in any case, a virtual blind spot in the regulation of NIPT.

\section{Materials and Methods}

In this study, the legislative and regulatory texts related to fetal anomaly screening and diagnosis in France since 1975, reports issued by public authorities (Agence de la Biomédecine-ABM, Comité Consultatif National d'Ethique-CCNE, Haute Autorité de Santé-HAS), and recommendations from scientific associations (Association des cytogénéticiens de langue française-ACLF-and Collège national des gynécologues et obstétriciens français-CNGOF) were examined. In addition, the newsletters of Fondation Lejeune, a French charity organization against the use of NIPT, were examined. Six semi-directive interviews were conducted in 2020 and 2021 with key actors in the field in France (four geneticists working in public and private laboratories, in hospitals or biomedical analysis companies, and two obstetricians). The interview questions were based on clinical and laboratory practices of NIPT and the elaboration of regulatory texts on the test ${ }^{3}$. The data analysis was performed with a sociological approach, i.e., the grounded theory [19]. This approach was complemented with a legal perspective, focusing on the regulation of public action and the development of standards in the innovation field.

\section{Results}

\subsection{Continuity: The Type of Governance}

\subsubsection{Professional Self-Regulation}

Since 1970, the importance of professional self-regulation has been a central feature of the development of prenatal diagnosis and screening $[17,20]$. In this complex field marked by continuous technical innovation, the public authorities, to design the regulatory framework for this activity, have largely relied on the expertise of professionals-doctors and researchers specializing in prenatal diagnosis and screening techniques-who have defined fetal T21 as a "public health problem."

The law that depenalized voluntary termination of pregnancy in 1975 also applied to medical termination of pregnancy, regardless of the length of the pregnancy. This was conditional on medical certification that the fetus was affected by "a particularly serious anomaly"; however, no list was drawn regarding the anomalies considered to be particularly serious (art. L. 2131-1 Public Health Code). To date, the Public Health Code does not contain any such list, leaving such assessments in the hands of medical professionals [21]. Since 1999, doctors have proceeded collectively, that is, the authorization to proceed with a termination of pregnancy on medical grounds is subordinated to the opinion of a Multidisciplinary Centre for Prenatal Diagnosis (Centre pluridisciplinaire de diagnostic prénatal [CPDPN]), which brings together several medical specialists

\footnotetext{
${ }^{3}$ Ethics approval is not required in France for this type of exploratory study.
} 
from major maternity hospitals under the supervision of the Biomedical Agency (Agence de la biomédecine-ABM).

The Ministry of Health then progressively granted reimbursement for various tests, such as fetal karyotype, ultrasound scan, serum markers, and combined testing (which consists of evaluating the risk of fetal $\mathrm{T} 21$ by combining the results of serum markers and the ultrasound scan measurements) [22]. As in other Western countries, testing for T21, which was reserved for high-risk older women, has been progressively extended to all pregnant women, leading to an invisible and a less-debated revolution [23]. In 2009, 9.5\% of births required invasive sampling (amniocentesis or trophoblast biopsy) to confirm or reject the high-risk testing result [24]. Therefore, this health policy has led to an increase in the diagnoses of anomalies other than T21 that are visible in fetal karyotypes.

Clinician-researchers in genetics and obstetrics, who have conducted clinical trials on prenatal testing in university hospitals, have made great efforts in providing pregnant women access to the tests. The public authorities have supported them by authorizing funding for all women under the public health insurance system. However, the authorities have paid much less attention to the quality of information passed on to pregnant women. A study indicated that compared with England and the Netherlands, consultations in France were of shorter durations, and front-line practitioners were less well-trained [17]. This trend has intensified since testing is performed at an earlier stage of pregnancy -in the first trimester. Presently, the concerned doctors are mainly general practitioners, midwives, and obstetrician-gynecologists working in private practice, with hospital doctors mainly treating women at the end of pregnancy; this applies to women suffering from chronic pathologies also. Private practitioners often work in isolation. When they do take the initiative to receive training, it is on the technical aspects of prenatal screening rather than on the communication with pregnant women. The term "non-directive counseling", common in the AngloAmerican world, has no direct translation in French. An approximate translation which is rarely used in obstetrics, would be "communication non directive." Only the term "informed consent", which pregnant women must give in writing, is used in France (consentement éclairé). The public authorities developed standard informed consent forms for serum markers in 1997 and combined testing in 2014.

\subsubsection{Approval of Health Authorities}

The regulation of NIPT is similar to the regulation of the previous tests for testing and diagnosing fetal anomalies. The public authorities rely on the expertise of clinician-researchers who form their views within the scientific associations of genetics and obstetrics (ACLF and CNGOF). These opinions evolve according to exchanges with French or foreign colleagues, companies in the sector, and women treated in consultations and who are offered the tests. Once these opinions reach a sufficiently broad consensus, the public authorities ratify them employing regulatory measures after consultation with various bodies, such as the Biomedical Agency (ABM), the National Consultative Ethics Committee (CCNE), or the French National Health Authority (HAS).

Based on the framework of CCNE, clinician-researchers have recommended the utilization of NIPT in France. This committee, consisting of researchers and doctors, is responsible for advising the Ministry of Health on the social acceptability of biomedical innovations [25]. The CCNE gave a favorable opinion on the use of NIPT to test T21, emphasizing the ability of this test to reduce the number of unnecessary and potentially dangerous invasive tests caused by the false-positive results 
of combined testing. The CCNE observed that the amniotic fluid and trophoblast samples are positive in less than $10 \%$ of cases. In the end, the opinion of the CCNE was favorable to the use of NIPT; however, a note was made stating that if the sequencing of larger regions of the genome or the entire fetal genome became technically and financially possible, this new test would lead to the detection of an "increasing number of chromosomal alterations and mutations associated with pathologies that are not always very serious" [26].

The influence of clinician-researchers was also decisive in the development of the screening strategy. The strategy was developed by the HAS, consisting of physicians and economists, which advises the government on the public financing of biomedical innovations. The latter aligned itself with the opinion of the scientific associations of genetics and obstetrics, which in 2015 and 2016 had recommended offering NIPT as a second-line procedure to women whose combined test results revealed a high probability of having a child affected with T21 [27, 28]. It was on this basis that, in 2017, the agency recommended the use of NIPT [29]. Thus, the new test is used to refine the results of the combined test, which continues to give many false-positive results. This strategy has also been adopted in other countries, but the originality of the French policy lies in the risk threshold used. In accordance with the recommendations of scientific associations, the HAS has set this threshold at a particularly low level, precisely 1/1000, to detect a greater number of fetal T21 [29]. This policy has resulted in greater activity for laboratories than with the previous threshold of $1 / 250$ ${ }^{4}$ due to an increase in the number of pregnant women being tested. In $2018,75,653$ women, i.e., $10 \%$ of pregnant women, were recommended to have a NIPT [30]. However, in line with its previous reports on prenatal testing, the HAS maintains that women's informed consent must be obtained before testing.

As the third step in the process of routine use of NIPT, coverage by the public health insurance system was decided by the Ministry of Health in 2018, in line with the conditions set by the HAS ${ }^{5}$. The Ministry also called for the software and reagents used to have the Conformité Européenne (CE) mark, a label of compliance with the European Union legislation.

While the public authorities have thus endeavored, in agreement with professionals, to regulate the access and quality of tests, they have paid little attention to the spectrum of anomalies targeted by the tests. Thus, the HAS report, dated 2017, only mentions testing for T21 and not for T13 and T18, even though at that time, professionals were already using NIPT to detect these two trisomies. The two ministerial orders that set out good practice in testing do not specify the field of exploration open to NIPT. The first, dated 25 January 2018, focuses on the modalities for implementing prenatal testing without setting a list of pathologies to be searched for, in accordance with the legislator's intent not to draw up an inventory of "conditions of particular seriousness". The order specifically mentions "non-invasive samples for the fetus" from "maternal blood making it possible to analyze,

\footnotetext{
${ }^{4}$ The rate of $1 / 250$ was used as a high risk-threshold for accessing diagnostic karyotype testing and for accessing NIPT in clinical trials. In the years 2015-2018, the new risk-threshold of 1/1000 gradually became popular in practice; at the same time, the use of NIPT expanded. After the release of the HAS report, the ministerial orders of 2018, which formalize the use of NIPT, endorsed this new risk-threshold.

5 See the decision of 19 April 2018 of the National Union of Health Insurance Funds (available from: https://www.legifrance.gouv.fr/jorf/id/JORFTEXT000037856379) and the ministerial orders of 25 January 2018 (available from: https://www.legifrance.gouv.fr/jorf/id/JORFTEXT000036559872) and 14 December 2018 (available from: https://www.legifrance.gouv.fr/jorf/id/JORFTEXT000037833062).
} 
in particular, the circulating fetal DNA" (§ 4. 1). The second order, dated 14 December 2018, recommends the test for T21 only. It specifies that the woman must be informed that "this testing is planned for trisomy 21 and not for other chromosomal anomalies" (§ II.A.2). However, it does not expressly exclude the possibility that NIPT may search for other conditions, as seems to be authorized by the previous order. It seems that the focus of the second order on T21 alone is to carefully regulate the condition rather than to limit NIPT to this indication, as testing for T21 is a politically sensitive matter in France. But this focus indicates the extent to which the health authorities have not addressed the potentialities of NIPT, even though the Ministry of Health had planned to ask the HAS again at a later date to evaluate the interest of testing for other aneuploidies.

\subsubsection{Low Investment by Legislators}

Similar to the previous prenatal testing techniques, which were little discussed in Parliament, the legislators did not invest much time on NIPT. In the end, contrary to what the initial work suggested ${ }^{6}$, the bioethics law, enacted on 29 June 2021, does not mention NIPT. This restraint on the part of the legislators contrasts with their investments in other areas related to human reproduction, such as medically-assisted procreation, which was the subject of heated debates when the government proposed opening it up to female couples or single women. Parliament's silence on prenatal testing also contrasts with the restrictive measures adopted on other related issues, such as the so-called recreational genetic tests to find out one's origins, predispositions in terms of preferences, and "online" medical tests (that remain prohibited in France). Parliament also adopted a restrictive approach for pre-implantation testing to detect chromosomal anomalies in embryos, which remains prohibited in the new bioethics law.

However, the new bioethics law has introduced a change, which could have consequences in terms of the number of anomalies targeted during testing. The law replaces the notion of "prenatal diagnosis" by that of "fetal medicine" and defines the latter not only as the detection of pathologies "of particular gravity" but also as "the diagnosis and prognostic evaluation, as well as, if necessary, the treatment, including surgical treatment, of a condition likely to have an impact on the future of the fetus or the unborn child" (new art. L. 2131-1 of the Public Health Code). This development is in response to a long-standing demand by obstetricians and sonographers that testing is not exclusively aimed at the termination of pregnancy. In some rare cases, fetuses can undergo a surgical operation in the uterus. However, the new bioethics law also signals a broadening of the range of anomalies sought during the diagnostic phase, by extending it to anomalies whose prognosis is uncertain and whose expressivity varies. While endorsing this development, the bioethics law makes no further specific mention of the extension of the pathologies sought during prenatal testing. Therefore, this question is tacitly delegated by the public authorities to doctors who are de facto responsible for establishing good practice on a subject that should have been evaluated and debated transparently by the legislators to arrive at a suitable decision. The setting aside of the legislative standard is all the more surprising when the market pressure is strong.

\footnotetext{
${ }^{6}$ See the report of the Mission d'information parlementaire led by J.-L. Touraine, Assemblée nationale, report $\mathrm{n}^{\circ} 1572$, 15 January 2019. See also the impact study, draft law on bioethics, 23 July 2019, NOR: SSAX1917211L.
} 


\subsubsection{Market Pressure}

The involvement of manufacturers in the regulation of prenatal testing is on the rise. Indeed, the development of NIPT has taken place in a very competitive context, as evidenced by the legal proceedings concerning patent issues between the players in the field [4]. The prenatal testing kits were introduced in the market by companies mainly from the US (Ariosa, Natera, Sequenom, and Verinata), and they sought to carefully protect their inventions. Some of these start-ups, founded by researchers, were then acquired by large companies from the pharmaceutical, biomedical, or sequencing equipment sectors, such as Illumina. Therefore, NIPT is part of a trend among genetic testing companies to preserve their intellectual property rights, which is in contrast to the policy developed up to then by most scientists in university hospitals of the US and Europe who were responsible for innovations in prenatal diagnosis and testing.

The economic stakes are indeed high. As the cost of NIPTs is high, they are likely to be used by pregnant women in high-income countries. In France, unlike other genetic tests for adults and children, NIPT is widely prescribed and performed in private practice, leading to their coverage by public or private insurance systems. In France, the public health insurance system covered 75,653 tests in 2018 [24] and 117,756 tests in 2020 [30] at a cost of 360 euros ${ }^{7}$. Test manufacturers are seeking to increase their market share by developing new versions of their products by focusing on two main areas of improvement-limiting analysis failures (uninterpretable results) and detecting a greater number of anomalies.

There is also competition among manufacturers of sequencing machines and reagents, who enter into partnership agreements with NIPT manufacturers. The American company Illumina has the largest share in the sequencing market in France, and its machines work with its Veriseq test. It has made a second version of its test available free of charge to laboratories that use its sequencers, which yield fewer uninterpretable results and detect a greater number of anomalies-rare trisomies and fragmentary chromosomal anomalies greater than seven megabases. Although the previous version is discontinued, testing laboratories are not required to activate the features of the second version. But eventually, Illumina's goal is to develop a test that identifies anomalies below seven megabases, such as Di George syndrome ${ }^{8}$, as other tests in the US already have this capability.

In addition, competition exists among medical biology laboratories that invest in sequencers and test kits to perform analyses. In France, two large companies, Cerba and Biomnis-Eurofins, perform $80 \%$ of the tests, as they receive blood samples sent by small medical analysis laboratories and hospitals. Cerba and Biomnis have acquired a license for Illumina's Veriseq tests. Apart from the private sector, only a few public sequencing platforms for NIPT exist such as in the Cochin University Hospital in Paris. This institution is part of the Assistance Publique Hôpitaux de Paris and uses the Illumina test for performing NIPT only for the dozen or so maternity units of this public group.

Driven by the desire to offer a broad-spectrum test in a competitive context, the large medical biology laboratories tend to follow the technical developments of the test manufacturers and offer to detect rare trisomies and deletions greater than seven megabases at the same price as the

\footnotetext{
7 See the decision of 19 April 2018 of the National Union of Health Insurance Funds supra.

${ }^{8}$ According to the 2020 information sheets forwarded by Illumina to healthcare professionals. These documents are not public and we are grateful to one of the geneticists interviewed for providing us with access to them.
} 
previous test ${ }^{9}$. For these companies, no legal obstacle exists in widening the number of anomalies sought since the health authorities have not taken a position on the subject, nor have they prohibited it. Thus, the choice is guided by medical (to judge the effectiveness of the new tests) and business responsibilities to position themselves in the market.

Ultimately, because of the low level of investment by the legislators, the regulation was largely delegated to the professionals in the sector, leading to an exacerbation of the classic model of prenatal testing regulation. Nonetheless, in the case of NIPT, this situation is coupled with a challenge-the constant widening of the scope of identified anomalies makes it all the more essential to inform pregnant women and to obtain their informed consent. However, this aspect remains a sort of blind spot in the regulation of NIPT.

\subsection{A Blind Spot: Consent to NIPT and Information Issues}

\subsubsection{Extension of Anomaly Detection and Evolution of Standards}

The companies manufacturing the test kits and machines and those performing the tests are engaged in competition not only to decrease the number of uninterpretable results but also to expand the number of anomalies detected. Like other prenatal testing techniques, such as ultrasound scans whose image accuracy is continuously improving, NIPT initially focused on detecting a small number of anomalies. Subsequently, the industry improved the tests to detect a larger number of anomalies.

Currently, scientific associations are stepping in to comment on new standards proposed by the industry. In 2019, the Association of French-speaking Cytogeneticists, which includes geneticists from public and private laboratories, modified its recommendations for good practice in NIPT, extending it to T13 and T18 [31]. In 2020, it issued new recommendations [32], and continued to advise against the study of sex chromosome anomalies, as these anomalies do not justify the medical termination of pregnancy (Klinefelter and Turner syndromes, for example). However, it recommended to detect seven additional rare trisomies.

While the spectrum of anomalies tested is gradually expanding, the scientific and medical community has not yet reached an agreement on the need to test for certain chromosomal imbalances, such as the fragmentary alterations greater than seven megabases. Some geneticists interviewed in this article recommend this extension, arguing that these chromosomal abnormalities are more common than T13 and T18, which can be detected with the existing tests. They also argue that testing for these alterations has a good sensitivity rate. In 2020 the ACLF did not specifically advise against testing for them and stated that if positive results were obtained, they should be discussed with the local CPDPN to determine the contents of the communication to the pregnant woman.

In reality, much diversity prevails in the practices followed. Some laboratories and hospitals test only for trisomy 13,18 , and 21 , while others target a much broader range of anomalies, including chromosomal rearrangements for which the ACLF has not reached an agreement. Similarly, while the ACLF has recommended that a positive result for trisomy seven should not be communicated to pregnant women, as this trisomy is confined to the placenta and, therefore, does not pose a risk to the fetus, this information is communicated by some biologists.

\footnotetext{
${ }^{9}$ One of them asked the health authorities for a price increase, but they refused.
} 
As evidence of this flexibility of professional standards and the time lag in the intervention by public authorities, the case of the American hospital in Paris was emblematic at that time. This private clinic, which caters to an international and national clientele, was the first to offer NIPT in France. From 2013 to 2018, the hospital used test kits from the American company Sequenom, which could detect various anomalies in addition to $T 21,13$, and 18 , including sex chromosome anomalies. The blood samples were sent to the US, where the results were stored, and the health authorities seemed to accept this practice. The American hospital admittedly stopped using the Sequenom test when in 2018, the government mandated that NIPT meet the CE mark standards. Furthermore, in the same year, the European General Data Protection Regulation came into effect, mandating that the test results must be stored in Europe. Therefore, the American hospital turned to a medical biology company in France, which directs patients who request more extensive tests to foreign solutions. It should be noted that it was not a regulatory limitation of the anomalies to be tested that led this institution to change its policy in terms of NIPT. Thus, the policy of the French public authorities is always characterized by a form of flexibility regarding the choice of anomalies to be tested.

Nevertheless, the extension of the number of anomalies sought by the various NIPTs raises questions concerning the information provided to the woman and the collection of her consent.

\subsubsection{The Renewed Challenge of Information and Consent}

In the above-described context, how can information and consent be arranged in such a way as to ensure that the pregnant woman has the means to make her own decision? In the case of NIPT, as in all prenatal testing, the Public Health Code ensures that the woman is informed and she gives her informed consent at each stage of the process, from the initial blood testing to the taking of amniotic fluid or trophoblast samples for diagnostic purposes in the event of a proven risk. The bioethics law of 7 July 2011 considerably reinforces the requirements for information, in particular on the objectives, methods, risks, limitations, and non-mandatory nature of the fetal monitoring examinations, before any consent is obtained from the pregnant woman (art. L. 2131-1 Public Health Code, II to VI). Thus, the function of the safeguards is clear-the carrying out of a test must always remain a personal choice ${ }^{10}$. But is this system sufficient in the case of NIPT? This question arises because the issue of consent is presented here in a new way.

First, NIPT is now routinely performed on women considered to be at risk, leading to a loss of information, making it more difficult to obtain informed consent. The more women are offered the test, the more it is performed by non-genetic professionals who are not trained in the particularities of this testing, leading to a strong reduction in prior information. However, detailed and comprehensive communication is fundamental: for T21, the predictive value of the test is very high; for trisomy 18 and 13, the predictive value is lower, decreasing even more for other trisomies and fragmentary chromosomal imbalances. Therefore, some information obtained from the test will be reliable and useful, while other data will be less so. Since the information document concerning

\footnotetext{
${ }^{10}$ Regarding NIPT, the 2018 order insists on information: "The information must be transmitted to the pregnant woman in oral and written form: see model (Order of December 14, 2018 amending the order of 14 January 2014 setting the model of documents mentioned in III of Article R. 2131-2 of the Public Health Code). At the end of the consultation, she is free to request or not the prescription of this testing by ADNIc. She must consent to its implementation in writing."
} 
NIPT prepared by the HAS only addresses T21 testing, It will be all the more difficult for pregnant women to appreciate such results [33].

Second, the knowledge acquired at an early stage about the chromosomal characteristics of the fetus places the pregnant woman in an unprecedented position. When NIPT is offered to a pregnant woman, she is not only put in a position to accept or reject the test but also to choose from the various targeted indications. This is the case with the Cerba form ${ }^{11}$, which is somehow "à la carte", because the woman can choose either a test limited to trisomies 13,18 , and 21 , or a test detecting not only these three trisomies but also duplications and deletions of more than seven megabases and rare trisomies $2,8,9,12,14,15,16$, and 22 . Similarly, the Eurofins Biomnis form ${ }^{12}$ states, "I have been informed that this test is not intended to reveal any conditions other than trisomy 21. However, the test performed will also test for trisomy 13 and 18. Sex chromosome aneuploidies are not reported. Other fetal or placental chromosomal anomalies (autosomal aneuploidies and imbalances greater than seven megabases) could eventually be identified." Therefore, it is up to the woman to say whether or not she wishes to know all or part of these anomalies, in accordance with the right of every patient to know or not to know.

Some criticize the position in which pregnant women find themselves. Can they interpret these forms, especially when they do not have a high level of education or when they lack the time and resources in their environment to understand the functioning of the health system? Can they really exercise their right not to have information about certain anomalies when faced with this type of wording? However, others welcome the decision-making autonomy granted to them. But in any case, it is clear that information and informed consent are of cardinal importance. However, if health professionals want to provide oral information that is understandable to the pregnant woman, it is costly in terms of time and training for them. How much time does the doctor prescribing the test have to explain to pregnant women all the subtleties of NIPT? A geneticist interviewed for this article revealed that she had to spend $45 \mathrm{~min}$ to explain the issues of the test to her patients correctly. Moreover, the consultations of professionals who follow pregnancies are often shorter.

In addition, practitioners are confronted with unanticipated challenges, particularly concerning what they report as results when these exceed what the woman has consented to. For example, in case of abnormal test results that have not been explicitly requested by the pregnant woman, should she be informed? Here we see a heterogeneity of practices, a sign of deep unease among biologists about how to proceed. According to one of our interviewees, some say nothing. Others provide for "catch-up possibilities", thereby implying to the prescriber that important results could be transmitted if the woman agrees "retrospectively." However, some will deliver the result in any event. Some public hospital geneticists have told us that they feel their hands are being "forced", as they receive anomaly results that fall beyond the indications they have requested.

Generally, practitioners are faced with the thorny issue of information that may appear incidentally during NIPT, without having been sought by the prescriber. For example, the profile of multiple anomalies identified by a NIPT suggests a maternal tumor that may turn out to be cancerous. The course of action is not codified to date, even if a certain interpretation of the new

\footnotetext{
${ }^{11}$ Cerba Information and consent form "Chromosomic anomalies screening by circulating fetal DNA analysis"

${ }^{12}$ Eurofins Biomnis Information and consent form. Testing for chromosomal anomalies by analysis of free circulating DNA.
} 
bioethics law could lead professionals to adopt a clear position and to inform all women before the testing. The law provides that where an examination of one's constitutional genetic characteristics is prescribed, the person shall be duly informed of "the possibility that the examination may incidentally reveal genetic characteristics unrelated to its initial indication or purpose, but whose knowledge would enable the person or members of his or her family to benefit from preventive measures, including genetic counseling, or from treatment" (art. 16-10, II. $3^{\circ}$, Civil Code). This new rule could apply to NIPT also, as it is an examination of the constitutional genetic characteristics of a person, such as $90 \%$ of the maternal constitutional DNA and $10 \%$ of the fetal DNA.

Therefore, the simplicity of NIPT, which is now routinely practiced, is in appearance only, and on many points, it raises questions similar to those posed by tests analyzing the genetic characteristics of adults [34, 35].

\section{Conclusion}

In France, the regulation of NIPTs is in line with that of previous prenatal testing techniques. Clinician-researchers introduce new tests from abroad in university hospitals or large private institutions. Also, they play a dominant role in defining the new testing standards that are gradually gaining the approval of the public bodies that oversee them, namely the health agencies and the Ministry of Health. Presently, parliament is not very involved in this regulation, even though NIPT is a tool that makes it possible to detect an increasing number of anomalies. This trend was also observed with previous techniques, in particular ultrasound scans. The use of NIPTs has currently intensified because of market pressure; this may pose a problem for certain clinicians who do not master the conditions for carrying out the tests and also for pregnant women for whom the information made available may be difficult to understand because of its technical nature. The regulation of previous prenatal testing techniques was already criticized for not always offering pregnant women the conditions for an informed choice in France. The use of NIPT makes these questions even more acute.

It must be ensured that, as is often the case in biomedical matters, the technological offer alone does not drive demand and create the needs of pregnant women [36]. Certainly, the relationship between innovation and social demand is complex, and "the whole history of innovation in medicine shows the necessary conjunction between an offer of medical interest and a corresponding, often non-explicit social demand" [37]. Given the importance of the intellectual and financial resources deployed to detect more and more anomalies at an ever earlier stage of pregnancy, it is important to ensure that the pregnant woman is sufficiently informed to make a choice. Otherwise, the notion of informed consent will become an empty shell. This is especially necessary as new testing techniques are being used to sequence the exome or whole fetal genome, from which other farreaching ethical issues arise [38].

\section{Author Contributions}

CN and LB conceptualized and designed the study. CN, CV and LB collected data, analyzed the data, and reviewed and revised the manuscript. CV drafted the initial manuscript. 


\section{Funding}

This article is based on a research project funded by the Agence de la biomédecine (2019 - 2021) entitled «Quel avenir pour le dépistage prénatal non invasif en France ? Analyse des normes et des pratiques médicales françaises au prisme du modèle belge».

\section{Competing Interests}

The authors have declared that no competing interests exist.

\section{References}

1. Ravitsky V, Roy MC, Haidar H, Henneman L, Marshall J, Newson AJ, et al. The emergence and global spread of noninvasive prenatal testing. Annu Rev Genomics Hum Genet. 2021; 22: 309338.

2. Holloway K, Miller FA, Simms N. Industry, experts and the role of the 'invisible college' in the dissemination of non-invasive prenatal testing in the US. Soc Sci Med. 2021; 270: 113635.

3. Löwy I. Non-invasive prenatal testing: A diagnostic innovation shaped by commercial interests and the regulation conundrum. Soc Sci Med. 2020. doi: 10.1016/j.socscimed.2020.113064.

4. Hawkins N, Nicol D, Chandrasekharan S, Cook-Deegan R. The continuing saga of patents and non-invasive prenatal testing. Prenat Diagn. 2019; 39: 441-447.

5. Christiaens L, Chitty LS, Langlois S. Current controversies in prenatal diagnosis: Expanded NIPT that includes conditions other than trisomies 13,18, and 21 should be offered. Prenat Diagn. 2021; 41: 1316-1323.

6. Perrot A, Horn R. The ethical landscape (s) of non-invasive prenatal testing in England, France and Germany: Findings from a comparative literature review. Eur J Hum Genet. 2021: 1-6. doi: 10.1038/s41431-021-00970-2.

7. Tabuteau D. Santé et liberté. Pouvoirs. 2009: 97-111. doi: 10.3917/pouv.130.0097.

8. Kliff $S$, Bhatia A. When they warn of rare disorders, these prenatal tests are usually wrong [Internet]. New York: The New York Times; 2022. Available from: https://www.nytimes.com/2022/01/01/upshot/pregnancy-birth-genetic-testing.html.

9. Gaudillière JP, Bettering babies. Down's syndrome, heredity and public health in post-war France and Britain. In: Images of disease: Science, public policy and health in post-war Europe, 25-28 November 1998. Brussels: European Comunnities; 2001. pp.89-108.

10. Champenois-Rousseau $B$, Vassy $C$. Les échographistes face au dépistage prénatal de la trisomie 21. Le difficile arbitrage entre excellence professionnelle et éthique du consentement. Sciences Sociales Et Santé. 2012; 30: 39-63.

11. Favre R. En quoi le niveau de connaissance médicale et la position des médecins respectent-ils ou non le consentement des patientes dans le cadre du dépistage de la Trisomie 21? Paris: Université de Paris; 2007.

12. Seror V, Ville Y. Prenatal screening for down syndrome: Women's involvement in decisionmaking and their attitudes to screening. Prenat Diagn. 2009; 29: 120-128.

13. Flori M, Farge T, Perdrix C, Aillaud A., Masson F. Diagnostic prénatal de la trisomie 21: Le vécu des patientes pendant l'attente des résultats. Rev Méd Périnat. 2012; 4: 126-131. 
14. Bertrand R. Le dépistage de la trisomie 21 est-il devenu un programme d'éradication [Internet]? Trisomie21.ORG; 2018. Available from: https://www.trisomie21.org/le-depistage-de-latrisomie-21-est-il-devenu-un-programme-d-eradication/.

15. Press N, Browner CH. Why women say yes to prenatal diagnosis. Soc Sci Med. 1997; 45: 979989.

16. Williams C, Alderson P, Farsides B. Is nondirectiveness possible within the context of antenatal screening and testing? Soc Sci Med. 2002; 54: 339-347.

17. Vassy C, Rosman S, Rousseau B. From policy making to service use. Down's syndrome antenatal screening in England, France and the Netherlands. Soc Sci Med. 2014; 106: 67-74.

18. Leblanc $P$. Tests sanguins précoces de dépistage: Comment préserver l'autonomie de décision de la femme [Internet]? Gènéthique, Paris; 2016. Available from:

https://www.genethique.org/tests-sanguins-precoces-de-depistage-comment-preserverlautonomie-de-decision-de-la-femme/.

19. Corbin J, Strauss A. Basics of qualitative research: Techniques and procedures for developing grounded theory. 3rd ed. Thousand Oaks: Sage, 2008

20. Steffen M. Genèse et conduite des politiques sociales. Handicap et vieillissement: Politiques publiques et pratiques sociales. Paris: INSERM; 1996.

21. Membrado M. La décision médicale entre expertise et contrôle de la demande: Le cas des interruptions de grossesse pour motif thérapeutique. Sciences Sociales et Santé. 2001; 19: 3161.

22. Vassy C. From a genetic innovation to mass health programmes: The diffusion of Down's syndrome prenatal screening and diagnostic techniques in France. Soc Sci Med. 2006; 63: 20412051.

23. Löwy I. Prenatal diagnosis: The irresistible rise of the 'visible fetus'. Stud Hist Philos Biol Biomed Sci. 2014; 47: 290-299.

24. ABM. Rapport d'activité annuel de DPN 2018. Available from: https://rams.agencebiomedecine.fr/sites/default/files/2020-09/200720_DPN2018 RAMS2020\%20VF.pdf.

25. Memmi D. Les gardiens du corps. Dix ans de magistère bioéthique. Paris: Editions de l'Ecole des Hautes Etudes en Sciences Sociales; 1996.

26. Basset C, Beaufils F, Dreifuss-netter F. Questions éthiques associées au développement des tests génétiques fœtaux sur sang maternel: Avis numéro 120. Comité Consultatif National d'Ethique pour les sciences de la vie et de la santé; 2013.

27. ACLF. Recommandations pour le dépistage non invasif des anomalies chromosomiques fœtales. 2015. Available from: http://www.eaclf.org/bulletin.php.

28. CNGOF. Recommandations pour I'utilisation de l'ADN fœtal circulant dans le sang maternel pour le dépistage de la Trisomie 21. Paris: CNGOF; 2016.

29. HAS. Place des tests ADN libre circulant dans le sang maternel dans le dépistage de la trisomie 21 foetale. Saint-Denis: HAS; 2017.

30. ABM. Rapport annuel d'activité de diagnostic prénatal. Rapport médical et scientifique procréation et génétique humaine en France. Saint-Denis: Agence de la biomédecine. 2020. Available from: https://rams.agence-biomedecine.fr/activite-des-laboratoires-decytogenetique-0.

31. ACLF. Recommandations pour le dépistage des anomalies chromosomiques fœtales par l'étude de l'ADN libre circulant (ADNIc). 2019. Available from: http://www.eaclf.org/bulletin.php. 
32. ACLF. Recommandations sur la conduite à tenir devant l'identification d'anomalies chromosomiques fœtales autres que les trisomies 13, 18 et 21 par l'étude de l'ADN libre circulant (ADNIc). 2020 Available from: http://www.eaclf.org/bulletin.php.

33. HAS. Le dépistage de la trisomie 21. Vous attendez un bébé. Saint-Denis: HAS; 2018.

34. Beaudevin C, Peerbaye A, Bourgain C. 'It has to become true genetics': Tumour genetics and the division of diagnostic labour in the clinic. Sociol Health IIIn. 2019; 41: 643-657.

35. Timmermans S, Tietbohl C, Skaperdas E. Narrating uncertainty: Variants of uncertain significance (VUS) in clinical exome sequencing. BioSocieties. 2017; 12: 439-458.

36. Conrad P. The medicalization of society: On the transformation of human conditions into treatable disorders. Baltimore: Johns Hopkins University Press; 2007.

37. Testart J. Des hommes probables. De la procréation aléatoire à la reproduction normative., Seuil, Paris, 1999: 72.

38. Horn R, Parker M. Opening Pandora's box? Ethical issues in prenatal whole genome and exome sequencing. Prenat Diag. 2018; 38: 20-25.

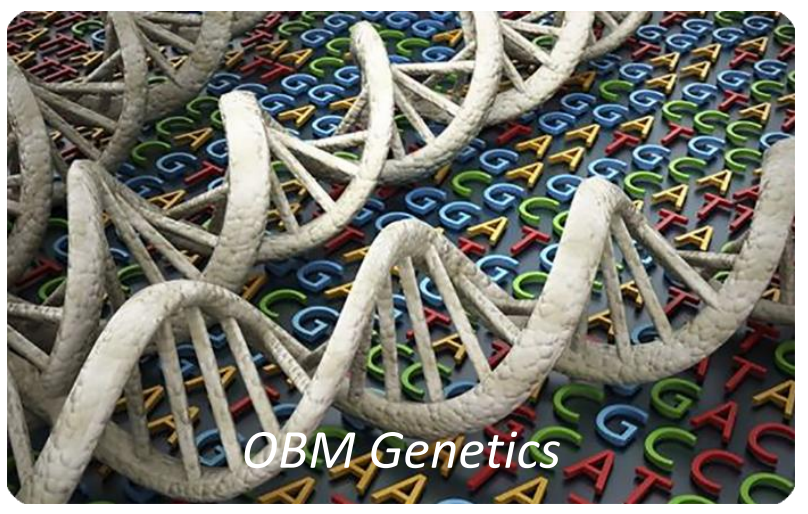

Enjoy OBM Genetics by:

1. Submitting a manuscript

2. Joining in volunteer reviewer bank

3. Joining Editorial Board

4. Guest editing a special issue

For more details, please visit:

http://www.lidsen.com/journals/genetics 